\title{
Dynamic Optimization of a Hybrid System of Energy-Storing Cryogenic Carbon Capture and a Baseline Power Generation Unit
}

\author{
Seyed Mostafa Safdarnejad ${ }^{\mathrm{a}}$, John D. Hedengren ${ }^{\mathrm{a}, *}$, Larry L. Baxter ${ }^{\mathrm{a}}$ \\ ${ }^{a}$ Department of Chemical Engineering, 350 CB, Brigham Young University, Provo, UT 84602, USA
}

\begin{abstract}
Recently promulgated regulations of the US Environmental Protection Agency (EPA) aggressively limit $\mathrm{CO}_{2}$ emissions from the US power industry. Carbon capture and increased utilization of renewable energy sources are viable approaches to reduce $\mathrm{CO}_{2}$ emissions from the power industry. Cryogenic carbon capture considered in this study is a post-combustion $\mathrm{CO}_{2}$ removal system that separates $\mathrm{CO}_{2}$ from the flue gas by desublimation. In this investigation, a hybrid system of cryogenic carbon capture and a baseline fossil-fueled power generation unit are optimized with a framework to mathematically represent this hybrid system. Optimization of this hybrid system results in meeting the electricity demand through a combination of coal, gas, and wind power sources with a priority given to wind power for utilization. A comparison of the cost associated with operating the steam turbine as a baseline or load-following unit is also made. A significant decrease in the cycling cost associated with load-following of the coal-fired power plant is observed when it operates as a baseline unit. The decrease in the cycling costs is $82 \%$ and $85 \%$, respectively, for when wind power is utilized in meeting the electricity demand and when it is not. The saving in the cycling costs is attributed to the energy storage of cryogenic carbon capture.
\end{abstract}

Keywords: Cryogenic Carbon Capture, Baseline Power Production, Dynamic

\footnotetext{
${ }^{*}$ Corresponding author. Tel.: +1 801477 7341, Fax: +1 8014220151

Email addresses: safdarne jad@byu . edu (Seyed Mostafa Safdarnejad), john. hedengren@byu . edu (John D. Hedengren), larry_baxter@byu . edu (Larry L. Baxter)
}

Preprint submitted to Applied Energy Journal

March 3, 2016

(C) 2016. This manuscript version is made available under the Elsevier user license http://www.elsevier.com/open-access/userlicense/1.0/ 
Optimization, Large-Scale Energy Storage

\section{Nomenclature}

\begin{tabular}{|c|c|}
\hline$C$ & Mass flow rate of the coal combustion \\
\hline$D^{C C C}$ & Total electricity demand for the CCC facility \\
\hline$D^{L N G}$ & Total electricity demand of the LNG production facility \\
\hline$D^{M R, C o m p}$ & Work of compression of the mixed refrigerant compressor \\
\hline$D^{N G, \text { Comp }}$ & Work of compression of the natural gas compressor \\
\hline$D^{N G, P i p e}$ & Work of compression of the pipeline compressor \\
\hline$D^{\text {plant }, \max }$ & Maximum fraction of the combined electricity demand of the LNG and CCC plants \\
\hline$D^{\text {plant }}$ & Combined electricity demand of the CCC and LNG production facilities \\
\hline$D^{\operatorname{Res}}$ & Electricity demand of the residential users \\
\hline$D^{\text {Tot }}$ & Total electricity demand \\
\hline$F G^{C}$ & Mass flow rate of the flue gas produced from coal combustion \\
\hline$F G^{N G, \max }$ & Maximum mass flow rate of the flue gas produced from natural gas combustion \\
\hline$F G^{N G}$ & Mass flow rate of the flue gas produced from natural gas combustion \\
\hline$F O M^{C T}$ & Fixed operating and maintenance costs of the coal-fired power generation unit \\
\hline$F O M^{G T}$ & Fixed operating and maintenance costs of the gas-fired power generation unit \\
\hline$G P_{\max }^{C C}$ & Maximum permitted power production in the combined cycle \\
\hline$G T^{c a p}$ & Capacity of the gas turbine \\
\hline$K^{N G}$ & Gain for the natural gas intake \\
\hline$K^{S T}$ & Gain for power production in the steam boiler \\
\hline$L N G^{B Y P}$ & Mass flow rate of the LNG bypassesing the tank \\
\hline$L N G^{\text {From Tank }}$ & Mass flow rate of the LNG from the tank \\
\hline$L N G^{\text {Prod }}$ & Mass flow rate of the LNG production \\
\hline$L N G^{\text {Tank }}$ & Mass of the LNG in the tank \\
\hline$L N G^{\text {To Tank }}$ & Mass flow rate of the LNG directed to the tank \\
\hline$L N G^{R}$ & Total mass flow rate of the LNG demand \\
\hline$M R$ & Mass flow rate of the mixed refrigerant \\
\hline
\end{tabular}




\begin{tabular}{|c|c|}
\hline$N G^{C C C}$ & Mass flow rate of the natural gas coming from the natural gas compressor \\
\hline$N G^{\text {Conv, } \max }$ & Maximum mass flow rate of the combusted natural gas \\
\hline$N G^{\operatorname{Conv} v}$ & Mass flow rate of the natural gas combustion in the gas turbine \\
\hline$N G^{E X P T}$ & Mass flow rate of the natural gas exported to the pipeline \\
\hline$N G^{\text {Onephase }}$ & Mass flow rate of the natural gas coming from the LNG/mixed refrigerant recuperator \\
\hline$N G^{P L, S P}$ & Set point of the natural gas imported from the pipeline \\
\hline$N G^{P L}$ & Mass flow rate of the natural gas imported from the pipeline \\
\hline$N G^{T o t}$ & Total mass flow rate of the natural gas for liquefaction \\
\hline$N G^{\text {Twophase }}$ & Mass flow rate of the two phase natural gas coming from the CCC plant \\
\hline$P^{C}$ & Coal price \\
\hline$P^{C T}$ & Power generated from the coal-generated flue gas \\
\hline$P^{E}$ & Energy price \\
\hline$P^{E x}$ & Excess power production \\
\hline$P^{G T}$ & Power production in the gas turbine \\
\hline$P^{N}$ & Natural gas price \\
\hline$P^{N G C C}$ & Power generated from the natural gas flue gas \\
\hline$P^{S P, M a x}$ & Upper bound for the set point of the power output from the coal-fired steam boiler \\
\hline$P^{S P}$ & Set point of the power output in the steam boiler \\
\hline$P^{S T}$ & Total power production in the steam boiler \\
\hline$P^{T o t}$ & Total power generation \\
\hline$P^{W}$ & Power generated from the wind \\
\hline$Q^{g}$ & Total heat gain in the recuperator \\
\hline$Q^{l}$ & Total heat loss in the recuperator \\
\hline$t$ & Time \\
\hline$V O M^{C T}$ & Variable operating and maintenance costs of the coal-fired power generation unit \\
\hline$V O M^{G T}$ & Variable operating and maintenance costs of the gas-fired power generation unit \\
\hline$\Delta H_{g}$ & Enthalpy of combustion of natural gas \\
\hline$\Delta H^{1}$ & Enthalpy difference of the cold natural gas across the recuperator \\
\hline$\Delta H^{2}$ & Enthalpy difference of the cold mixed refrigerant across the recuperator \\
\hline$\Delta H^{3}$ & Enthalpy difference of the warm natural gas across the recuperator \\
\hline
\end{tabular}


$\Delta H^{4} \quad$ Enthalpy difference of the warm mixed refrigerant across the recuperator

$\Delta H_{F G}^{N G} \quad$ Specific enthalpy change of the flue gas from combustion of natural gas

$\Delta H_{F G}^{C} \quad$ Specific enthalpy change of the flue gas from combustion of coal

$\epsilon_{g}$

Efficiency of power production in the gas turbine

$\epsilon^{S B} \quad$ Efficiency of the heat exchange in steam reboiler

$\eta^{S T} \quad$ Efficiency of the steam turbine

$t_{a u} u^{N G} \quad$ Time constant for the natural gas intake

$\tau^{S T} \quad$ Time constant for power production in the steam boiler

CCC Cryogenic carbon capture

CCCECL Cryogenic carbon capture with an external cooling loop

CCS Carbon capture and storage

CHP Combined heat and power unit

EGS Enhanced geothermal system

EPA Environmental Protection Agency

$\mathrm{HHV} \quad$ Higher heating value

IE A International Energy Agency

IGCC Integrated Gasification Combined Cycle

LCOE Levelized Cost of Electricity

LNG Liquefied natural gas

NG Natural gas

NGCC Natural gas combined cycle

OCR Organic Rankine cycle

PC Pulverized Coal

SAPG Solar Aided Power Generation

\section{Introduction}

The power sector is one of the main sources of $\mathrm{CO}_{2}$ emission. The International Energy Agency (IEA) estimated $42 \%$ of the 2012 global $\mathrm{CO}_{2}$ emissions are derived from power and heat production [1]. There is nearly universal agreement among 
5 climatologists that anthropomorphic $\mathrm{CO}_{2}$ and other greenhouse gases are the main causes of global warming [2] As a result, more restrictive regulations for $\mathrm{CO}_{2}$ emissions have been enforced or are under consideration [3, 4, 5]. Recently the US Environmental Protection Agency (EPA) promulgated regulations under Clean Air Act Sections 111 (b) and 111(d) for the $\mathrm{CO}_{2}$ emissions from the US power industry. Existing natural gas and coal-fired power plants can emit up to 1100 and $1400 \mathrm{lbs}$ of $\mathrm{CO}_{2}$ per $M W h$ energy generation. New power plants must reduce $\mathrm{CO}_{2}$ emissions by $20 \%$ from 2014 levels [3]. Current combined-cycle natural gas plants meet these standards and they are about $30 \%$ below the emissions of most coal plants. Such large reductions from coal plants lie well beyond the reach of plant efficiency improvements or other modest operational changes and threaten decommissioning of existing plants and curtailing plans for new plants. In fact, coal consumption has declined in the US for many years and there are very few new coal plants planned. These declines, however, stem from low-cost natural gas competition and not from $\mathrm{CO}_{2}$ emissions controls. Low-cost natural gas is a recent development in the US but is not a global shift in the energy landscape. Globally, coal is by far the most rapidly growing source of primary energy [2]. The trend of the global coal trade is mainly driven by countries in Asia, specifically China and India. For instance, these two countries accounted for 98\% of the increase in world coal trade from 2008 to 2013. The increase in the imported coal in China and India is primarily due to an increase 25 in the electricity generation and steel manufacturing [6]. In the US, coal is projected to play a major role in power generation by EPA projections, and shows every sign of continuing a rapidly increasing role in power globally. Global $\mathrm{CO}_{2}$ emissions must decrease by $60-80 \%$ to limit global climate change to a $2{ }^{\circ} \mathrm{C}$ increase [7]. This is about twice as much as the total $\mathrm{CO}_{2}$ emissions from all forms of power generation. Therefore, global climate change critically depends on finding ways to reduce $\mathrm{CO}_{2}$ emissions from fossil power plants generally and from coal specifically. In this sense, fossil- and specifically coal-based emissions reduction represents one of the most important elements of climate change mitigation. No national or global climate change policy can likely succeed without addressing this issue. 
emission level. The literature for $\mathrm{CO}_{2}$ removal mainly considers three typical CCS technologies: post combustion, pre-combustion, and oxyfuel [2]. The common processes considered in post-combustion technologies are based on using chemical and physical absorption [8, 9, 10, 11, 12, 13, 14, 15, 16, 17, 18, 19] or membranes 20. 21]. Pre-combustion technologies are mostly considered in integrated gasification combined cycle (IGCC) power plants, and they are based on removing $\mathrm{CO}_{2}$ from the fossil fuels before combustion [22, 23]. In oxyfuel technologies, pure oxygen is used to combust the fuel [24, 25]. Cryogenic technologies have also been considered for carbon dioxide removal, and they have several forms such as an inertial carbon extraction system, a thermal swing process, and cryogenic carbon capture with an external cooling loop (CCCECL) [26, 27]. In this investigation, the latter category of cryogenic capture process is considered for removing $\mathrm{CO}_{2}$ from the flue gas of power plants.

The CCC process is a novel technology for carbon dioxide removal from the flue gas of power generation units [28]. The CCC process cools flue gas from power generation units to the point that $\mathrm{CO}_{2}$ desublimates. The process then separates solid $\mathrm{CO}_{2}$ from the remaining gas and melts it. Both the remaining flue gas and pressurized solid $\mathrm{CO}_{2}$ warm back to higher temperatures. Fast response to fluctuations in electricity demand and renewable energy sources, lower energy consumption and 55 cost, and energy storage are the main advantages of the CCC process. Integration of the CCC capture process with a coal-fired steam boiler that is able to follow the load is considered in [29, 30,31]. However, many coal-fired generation units operate in a baseline mode and the power output from those generation units is approximately constant over most of the operational lifetime. This investigation considers the integration of a baseline coal-fired steam boiler with a cryogenic capture process. Considering energy storage, the hybrid system is also able to follow the peak demand with a gas turbine without necessarily cycling the coal-fired steam boiler. This is a distinguishing feature of this work from the previous investigation [29]. In addition, the model developed for this hybrid system is applicable to both baseline 65 and load-following generation units. Minor adjustments to the model make boiler output constant or load-following. A comparison is also made between power pro- 
duction in simple (scenario 2) and combined (scenario 1) cycles. The simple cycle is a typical peaking unit that is integrated with a baseline steam turbine and the $\mathrm{CO}_{2}$ emission from both units is mitigated by a cryogenic capture process without energy storage. The results from this comparison highlights the significance of energy storage capability of the CCC process. Finally, the costs associated with cycling a power generation unit are studied, and the impact of the energy storage capability of the CCC process on the cycling costs is quantified. Cycling costs analysis is considered with both presence and absence of the wind power in partially meeting the electricity demand.

This paper is divided into five sections. First, the CCC process is briefly reviewed. Then, the modeling and optimization frameworks to represent the hybrid system are developed. Next, the optimization results obtained for an integrated system of a baseline power generation unit and the CCC process are presented. A comparison between power production in the gas turbine through a simple or combined cycle is also made. Finally, the impact of energy storage of cryogenic carbon capture on leveling the power output from a steam turbine and the associated savings are discussed. It is observed that with the energy storage, a saving of $82 \%$ (with wind power) and $85 \%$ (without wind power) in the cycling costs associated with the loadfollowing of a steam turbine are obtained.

\section{CCC Capture Process}

As mentioned, the CCC process separates $\mathrm{CO}_{2}$ from the power plant flue gas by a desublimation process. Two refrigeration cycles are used to provide the cooling medium for the desublimation process (see Figure 1). The internal refrigeration cycle is operated by a typical refrigerant such as $\mathrm{CF}_{4}$. Several selections could be made for the refrigerant of the external loop. One selection, liquefied natural gas (LNG), adds significant value and flexibility to the hybrid system. Selection of LNG for the external cooling loop permits the hybrid system to take natural gas from a pipeline and produce LNG in a liquefaction facility. However, the liquefaction process is a 
is high. An insulated tank can time-shift LNG production to off-peak hours. When electricity demand is low, the CCC process produces excess LNG and stores the excess in the insulated tank. Similarly, renewable power sources, even when intermittently available, provide electricity for the liquefaction process. In both cases, lowcost electricity is used to generate carbon capture refrigerant in the form of LNG. During peak hours, the CCC process uses stored LNG for the capture process and delivers the decreased parasitic load to the grid. Removal of heat from the flue gas causes the LNG to become a two phase natural gas stream (stream 9 in Figure 1]. This two phase stream completely vaporizes and reaches a higher temperature with further heat gain in the LNG/mixed refrigerant (MR) recuperator. The outlet natural gas from the LNG/MR recuperator (stream 10 in Figure 1 ) can be partially combusted in a gas turbine. This adds load-following capability to a coal-fired power generation unit equipped with the CCC capture process without necessarily needing to cycle the coal-fired steam boiler. The remaining natural gas from the LNG/MR recuperator (stream 13 in Figure 1) can also be recirculated to the LNG production facilities or be exported to pipeline (stream 1 in Figure 1 ) to avoid processing it when electricity is expensive. At each time either the storage or a recovery mode is in operation and decision about the operating mode is based on the economical evaluation of the hybrid system. The CCC process and the associated refrigeration cycles are investigated in [26, 32]. Integration of the CCC process with a load-following generation unit is also discussed in [29, 30, 31]. Different designs for the LNG production facilities are presented in $33,34,35$ and are applicable to a hybrid system of CCC and power generation units.

\section{Model Framework}

\subsection{Hybrid System Model}

In this section the model developed for the hybrid system of the power generation unit and the CCC capture process is presented. First, relationships for power generation from each source are developed and are all presented in units of $M W$. This is followed by relationships for fuel consumption and flue gas production from 


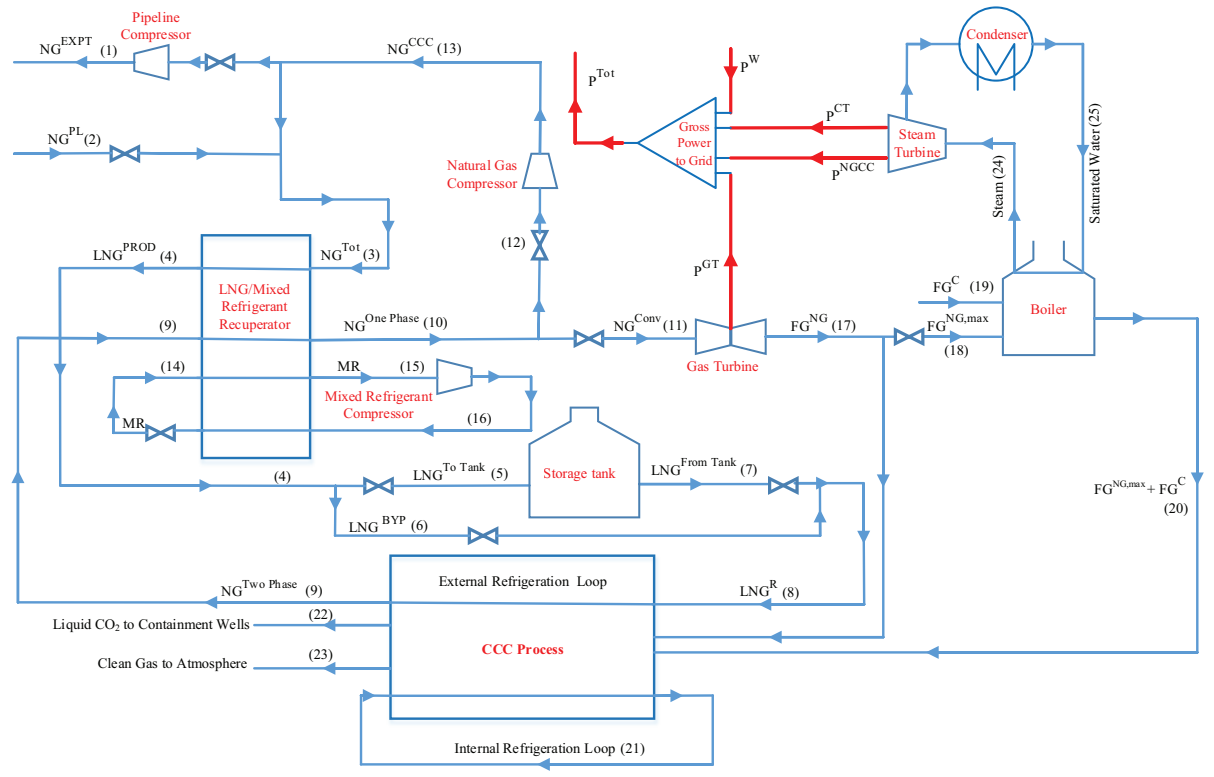

Figure 1: Schematic configuration of the hybrid system of a power generation unit and CCC, 29

each fuel supply. Next, equations are developed for the calculation of electricity demand for different components of the CCC and LNG plants and mass balance equations for different points in Figure 1 . Additionally, details of an energy balance on the LNG/mixed refrigerant recuperator are given along with details of the objective function of this optimization problem. This section concludes with a discussion on the controlled variables, constraints, and optimization framework.

\subsubsection{Power Generation From Coal}

The power production in the coal-fired steam boiler $\left(P^{S T}\right)$ is calculated from a first order differential equation (Eq. 11) that relates the power output $\left(P^{S T}\right)$ to the set point of the power output $\left(P^{S P}\right)$. This relation represents the transient response of steam boilers when a change in the power output is required. The set point of the steam boiler power output $\left(P^{S P}\right)$ is a decision variable and is optimized based on the economical evaluation of the hybrid system. The range of variation of $P^{S P}$ is considered between 800 and $1800 \mathrm{MW}$ and is assumed based on a maximum residential electricity demand of $2000 M W$ [29]. When integrating the CCC capture process with existing power generation units, this range should be modified according to 
the capacity of the steam turbine.

$$
\tau^{S T} \frac{d P^{S T}}{d t}=-P^{S T}+K^{S T} P^{S P}
$$

In this case, $\tau^{S T}$ and $K^{S T}$ are the time constant and gain, respectively, for power production in the steam boiler. The time constant represents the time it takes to reach $63.2 \%$ of the total change in steam boiler power output when there is a change

145 boiler and the magnitude of change in the set point. An assumed value of 2 hours for the time constant represents the slow response of steam boilers to changes in set points in practice. A gain value of 1 is used in Eq. (1) for the steam boiler. It should be noted that reference to the power production in a steam boiler $\left(P^{S T}\right)$, in this investigation, is in fact the result of producing power in a turbine that is driven by the steam generated in the boiler. Steam is generated from the heat content of the flue gas produced from coal combustion. Exiting flue gas from a gas turbine can also be introduced to the boiler to produce more steam and achieve the efficiency of a combined cycle. Thus, total power output from the steam turbine $\left(P^{S T}\right)$ is the summation of equivalent power from exchanging heat by the flue gas generated from coal and natural gas combustion (Eq. 2)).

$$
P^{S T}=P^{C T}+P^{N G C C}
$$

$P^{C T}$ and $P^{N G C C}$ are the power generated from the coal and natural gas flue gases, respectively. As presented by Eqs. (4) and [5, $P^{N G C C}$ is dependent on the rate of natural gas combusted in the gas turbine, $N G^{\operatorname{Conv}}$, (or equivalently on the gas power production, $P^{G T}$ ). Either $P^{C T}$ or $P^{G T}$ can be selected as the second decision variable and the other variable (as well as $P^{N G C C}$ ) is calculated from solving Eqs. (2) and (4) simultaneously. Similarly, mass flow rates of combusted coal (C) and natural gas $\left(N G^{C o n v}\right)$ can be selected as the second decision variable. In this investigation, flow rate of the natural gas combusted in the gas turbine is selected as 


\subsubsection{Power Generation From Natural Gas}

Power generated in the gas turbine, $P^{G T}$, is calculated from Eq. (3):

$$
P^{G T}=N G^{\operatorname{Conv}} \epsilon_{g} \Delta H_{g}
$$

where $\epsilon_{g}, \Delta H_{g}$ are the efficiency of power production in the gas turbine and enthalpy of combustion of natural gas, respectively. The values assumed for these two

$$
F G^{C}=\frac{P^{C T}}{\epsilon^{S B} \eta^{S T} \Delta H_{F G}^{C}}
$$


where $F G^{C}$ and $\Delta H_{F G}^{C}$ are the mass flow rate of the flue gas from coal combustion and specific enthalpy change of the flue gas, respectively. It is also assumed that $10.93 \mathrm{~kg} / \mathrm{hr}$ flue gas is produced from the combustion of $1 \mathrm{~kg} / \mathrm{hr}$ of coal (Eq. 7)).

$$
C=\frac{F G^{C}}{10.93}
$$

\subsubsection{Electricity and LNG Demands}

Next, electricity demand of the CCC and LNG production facilities and the LNG requirement to treat the flue gas are calculated. The electricity demand for the CCC 
Table 1: Summary of the input parameters

\begin{tabular}{|c|c|}
\hline Thermal efficiency of boiler, $\epsilon^{S B}$ & 0.88 \\
\hline Efficiency of the steam turbine, $\eta^{S T}$ & 0.416 \\
\hline $\begin{array}{l}\text { Specific enthalpy change of the flue gas } \\
\text { from coal combustion, } \Delta H_{F G}^{C} \text {, (MJ/kg) }\end{array}$ & 2.335 \\
\hline Efficiency of the gas turbine, $\epsilon_{g}$ & 0.3275 \\
\hline $\begin{array}{l}\text { Enthalpy of combustion of natural gas } \\
\qquad(\mathrm{HHV}), \Delta H_{g}(\mathrm{MJ} / \mathrm{kg})\end{array}$ & 53.89 \\
\hline $\begin{array}{l}\text { Specific enthalpy change of the flue gas } \\
\text { from natural gas combustion, } \Delta H_{F G}^{N G}(\mathrm{MJ} / \mathrm{kg})\end{array}$ & 0.587 \\
\hline$G P_{\max }^{C C}(M W)$ & $\begin{array}{l}360 \text { ( } 20 \% \text { of the upper bound for } \\
\text { the steam turbine power output) }\end{array}$ \\
\hline Maximum residential electricity demand $(M W)$ & 2000 \\
\hline Overall efficiency of coal-fired power plant & $36.8 \%$ \\
\hline Overall efficiency of the NGCC power plant & $50.2 \%$ \\
\hline $\begin{array}{c}\text { Work of compression for natural gas } \\
\text { compressor }\left(\mathrm{kWh}_{\mathrm{e}} /(\mathrm{kg} \text { inlet })\right) \text { or }\left(\mathrm{GJ}_{\mathrm{e}} / \text { tonne } \mathrm{CO}_{2}\right)\end{array}$ & $0.051(0.1656)$ \\
\hline $\begin{array}{l}\text { Work of compression for mixed refrigerant } \\
\text { compressor }\left(\mathrm{kWh}_{\mathrm{e}} /(\mathrm{kg} \text { inlet })\right) \text { or }\left(\mathrm{GJ}_{\mathrm{e}} / \text { tonne } \mathrm{CO}_{2}\right)\end{array}$ & $0.077(0.1818)$ \\
\hline $\begin{array}{l}\text { Work of compression for pipeline compressor }\left(\mathrm{kWh}_{\mathrm{e}} /(\mathrm{kg}\right. \\
\text { inlet }))\end{array}$ & 0.01 \\
\hline $\begin{array}{l}\text { Electricity demand of the CCC for treatment } \\
\text { of the flue gas (coal combustion) }\left(\mathrm{GJ}_{\mathrm{e}} / \text { (tonne } \mathrm{CO}_{2} \text { captured)) }\right.\end{array}$ & 0.389 \\
\hline
\end{tabular}

Electricity demand of the CCC for treatment

of the flue gas (gas combustion) $\left(\mathrm{GJ}_{\mathrm{e}} /\right.$ (tonne $\mathrm{CO}_{2}$ captured))

LNG demand to process the coal flue gas (kg/ (tonne $\mathrm{CO}_{2}$ captured))

856

LNG demand to process the gas flue gas $\left(\mathrm{kg} /\right.$ (tonne $\mathrm{CO}_{2}$ captured))

\begin{tabular}{cc}
\hline Coal price $(\$ /$ ton $)$ & 12.65 \\
\hline Natural gas price $\left(\$ / 1000 \mathrm{ft}^{3}\right)$ & 5.19 \\
\hline Gas turbine capacity $\left(G T^{c a p}\right)(M W)$ & 1000 \\
\hline
\end{tabular}


plant includes the energy requirement for compression of the separated $\mathrm{CO}_{2}$, compressors in the internal refrigeration cycle, and other auxiliary units not shown in Figure 1 The total energy requirement for the compression of recirculating natural gas, mixed refrigerant, and exported natural gas is referred to as the LNG plant electricity demand. These streams are shown in Figure 1 as stream 12, 15, and 1, respectively.

While the power production from natural gas in a combined cycle is limited, all the flue gas produced in the gas turbine should be treated in the CCC process. Thus, total electricity demand of the CCC process and the required LNG to treat the flue gas resulting from the combustion of natural gas are based on $N G^{\text {Conv }}$ and are calculated from the re-arrangement of Eq. (5). It is assumed that the treatment of hot flue gas from the gas turbine and the cold flue gas from the steam boiler requires the same amount of electricity and LNG. According to [29], 0.389 and 0.428 GJ electricity are required in the $\mathrm{CCC}$ plant to capture one tonne of $\mathrm{CO}_{2}$ from the flue gases generated by combustion of coal and natural gas, respectively. Adopting the combustion reaction mechanisms used by [9], 851.23 and $545.47 \mathrm{~kg} / \mathrm{hr} \mathrm{CO}$ is produced from one $M W$ power generation from coal and natural gas, respectively. With a $90 \%$ capture rate, the electricity demands of the CCC plant for treatment of the flue gases generated from coal and natural gas combustion are 0.083 and 0.058 per $M W$ generated power from each source, respectively. The overall electricity demand for the CCC facility is then calculated from Eq. 10]:

$$
D^{C C C}=0.083 P^{C T}+0.058 P^{N G C C}
$$

According to [29], required LNG to process the flue gases from coal and natural gas combustion are 856 and $685 \mathrm{~kg}$ per tonne $\mathrm{CO}_{2}$ captured. Similar to the calculation of the CCC electricity demand, LNG demand for treatment of the flue gas from combustion of coal and natural gas are 656.2 and $336.4 \mathrm{~kg} / \mathrm{hr}$ per one $M W$ generated power from each source, respectively. Thus, the overall LNG demand is calculated 
from Eq. (11):

$$
L N G^{R}=656.2 P^{C T}+336.4 P^{N G C C}
$$

The work of compression of the natural gas $\left(D^{N G, \operatorname{Comp}}\right)$ and mixed refrigerant $\left(D^{M R, C o m p}\right)$ compressors are 0.1656 and $0.1818 \mathrm{GJ}_{\mathrm{e}}$ per tonne of the captured $\mathrm{CO}_{2}$ ( 0.051 and $0.077 \mathrm{~kW}$, respectively, based on $\mathrm{kg} / \mathrm{hr}$ of the inlet streams). Work of compression of the pipeline compressor is also $0.01 \mathrm{~kW}$ per $\mathrm{kg} / \mathrm{hr}$ of the inlet stream [29]. After unit conversion, these lead to the following equations:

$$
\begin{gathered}
D^{N G, \text { Comp }}=5.1 \times 10^{-4} N G^{C C C} \\
D^{M R, \text { Comp }}=7.7 \times 10^{-5} M R \\
D^{N G, \text { Pipe }}=1 \times 10^{-5} N G^{E X P T}
\end{gathered}
$$

where $N G^{C C C}, M R, N G^{E X P T}$ are the mass flow rates of natural gas coming from the CCC process, mixed refrigerant, and natural gas exported to the pipeline, respectively (Figure 1 .

It should be emphasized that the $\mathrm{CO}_{2}$ removal process is assumed to be a continuous operation. Thus, the CCC plant electricity demand, $D^{C C C}$, always exists. Regardless of the energy storage, energy requirement for compression of the recirculating natural gas, $D^{N G, \text { Comp }}$, also always exists. This is because of the continuous need of the capture plant for LNG which generates a continuous flow of natural gas inside the system, presented by streams 9, 10, 12, and 13 in Figure 1 Energy storage only shifts some of the electricity demand of the mixed refrigerant compressor $\left(D^{M R, \operatorname{Comp}}\right)$.

Total electricity demand for capturing $\mathrm{CO}_{2}, D^{\text {plant }}$, is then calculated by adding up the individual components (Eq. [15):

$$
D^{\text {plant }}=D^{C C C}+D^{N G, \text { Comp }}+D^{M R, \text { Comp }}+D^{N G, \text { Pipe }}
$$




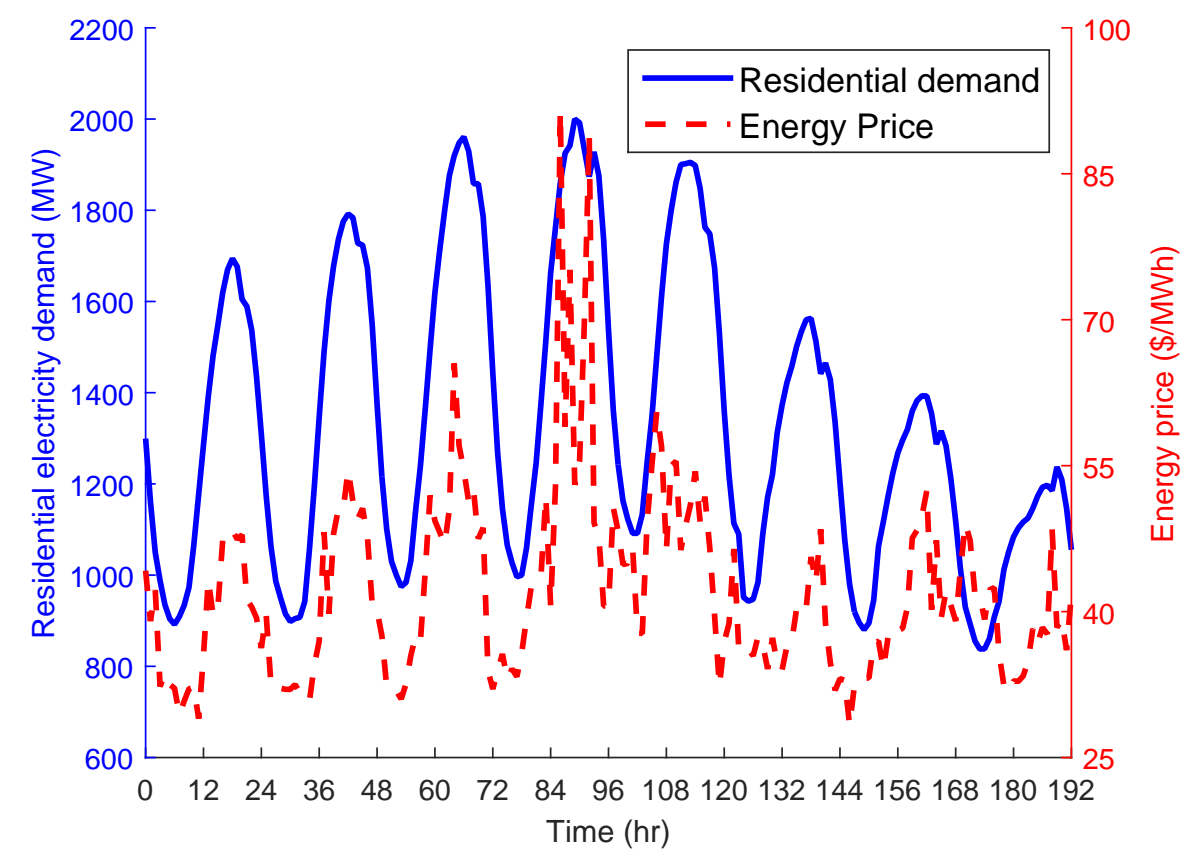

Figure 2: Actual electricity demand for San Diego, USA, and average energy price for California for the period between September 13, 2014 and September 20, 2014 [29].

Total electricity demand is a summation of the CCC and LNG plants, $D^{\text {plant }}$ and residential area, $D^{\text {Res }}$, presented by Eq. 16. Residential electricity demand assumed in this investigation is an input to the optimization problem. The data used for the residential demand is shown in Figure 2 and is based on the scaled electricity demand for San Diego, USA for the period between September 13, 2014 and September 20, 2014 [37].

$$
D^{\text {Tot }}=D^{\text {plant }}+D^{\text {Res }}
$$

\subsubsection{Total Power Generation}

The overall power generation is also calculated from Eq. 17):

$$
P^{T o t}=P^{C T}+P^{G T}+P^{N G C C}+P^{W}
$$


where $P^{W}$ represents the power generated from the wind and is considered an input to the model. A wind power profile similar to the previous work [29] is adopted sources in Section 4

\subsubsection{LNG Production and Storage Facilities}

Mass balance equations for different points in the LNG production and storage facilities are presented next. According to Figure 1 , the amount of LNG that is produced in the recuperator (stream 4) is the sum of the natural gas imported from the pipeline (stream 2) and natural gas that comes from the CCC plant (stream 13). From this summation, natural gas exported from the plant (stream 1) should be deducted. Thus, total LNG production (also equals the value of $N G^{T o t}$ on a mass basis) is calculated from Eq. [18):

$$
L N G^{\text {Prod }}=N G^{P L}+N G^{C C C}-N G^{E X P T}
$$

275

Deriving all equations on a mass basis also results in the equality of $N G^{\text {Twophase }}$, $N G^{\text {Onephase }}$, and $L N G^{R}$ (Figure 1). This conclusion is used in deriving a relationship between $N G^{C C C}, L N G^{R}$, and $N G^{C o n v}$. It is obvious from Figure 1 that natural gas from the CCC plant (stream 13), $N G^{C C C}$, equals the difference between mass flow rates of the LNG requirement (stream 10), $L N G^{R}$, and natural gas combusted in the gas turbine (stream 11), $N G^{\operatorname{Con} v}$ :

$$
N G^{C C C}=N G^{\text {Onephase }}-N G^{\text {Conv }}
$$

The LNG production (stream 4) is also equal to the summation of the LNG to the tank (stream 5) and the LNG bypassing the tank (stream 6) (Eq. 201):

$$
L N G^{\text {Prod }}=L N G^{\text {To Tank }}+L N G^{B Y P}
$$

LNG from the tank (stream 7) is calculated from a mass balance at the tank outlet 
Eq. 21):

$$
L N G^{\text {From Tank }}=L N G^{R}-L N G^{B Y P}
$$

A dynamic mass balance equation is also used for defining the inventory of the tank (Eq. 22)):

$$
\frac{d\left(L N G^{\text {Tank }}\right)}{d t}=L N G^{\text {To Tank }}-L N G^{\text {From Tank }}
$$

\subsubsection{Natural Gas Intake}

While combustion of the natural gas in the gas turbine is approximately instantaneous, an equation similar to Eq. (1) is considered for the natural gas imported to the plant (Eq. 23)). This equation represents the dynamic response of the system to changes in set point of imported natural gas.

$$
\tau^{N G} \frac{d N G^{P L}}{d t}=-N G^{P L}+K^{N G} N G^{P L, S P}
$$

where $N G^{P L, S P}$ is the set point of the natural gas imported from the pipeline and is a decision variable. Time constant and gain of the first order model used in this equation are represented by $\tau^{N G}$ and $K^{N G}$, respectively. A time constant of 5 minutes and a gain value of 1 are assumed for the import of natural gas.

\subsubsection{LNG/Mixed Refrigerant Recuperator}

An energy balance over the recuperator defines the relationship between the natural gas imported $\left(N G^{P L}\right)$, exported $\left(N G^{E X P T}\right)$, and recirculated in the system $\left(N G^{C C C}\right.$ ). It also defines the trend of variation of mass flow rate for the mixed refrigerant $(M R)$. Total energy gain from the cold streams entering the recuperator is obtained from Eq. 24]:

$$
Q^{g}=N G^{\text {Twophase }} \Delta H^{1}+M R \Delta H^{2}
$$

where $\Delta H^{1}$ is the enthalpy difference of the two phase gas stream exiting the CCC plant and warm natural gas after the recuperator and is equal to $299 \mathrm{~kJ} / \mathrm{kg}$. $\Delta H^{2}$ is 
also the enthalpy difference of the cold mixed refrigerant entering the recuperator and is equal to $620 \mathrm{~kJ} / \mathrm{kg}$.

Total energy loss from the hot streams entering the recuperator is also obtained from Eq. 25):

$$
Q^{L}=N G^{T o t} \Delta H^{3}+M R \Delta H^{4}
$$

where $\Delta H^{3}$ is the enthalpy difference between the warm natural gas that is liquefied and the LNG produced in the plant and is equal to $-582 \mathrm{~kJ} / \mathrm{kg}$. $\Delta H^{4}$ is also the enthalpy difference of the hot mixed refrigerant entering the recuperator and is equal to $-9 \mathrm{~kJ} / \mathrm{kg}$.

The values assumed for $\Delta H^{1}, \Delta H^{2}, \Delta H^{3}$, and $\Delta H^{4}$ are based on the results obtained at [26] with the assumption that temperature and pressure of the entering and exiting streams to and from the recuperator are constant. Results presented in [38. 39] propose a design for a plate heat exchanger that the temperature and pressure remain constant despite the fluctuations in inlet and outlet conditions of the heat exchanger. Thus, the recuperator considered in this study has a steady state performance and is very responsive to fluctuations in the inlet and outlet conditions of the recuperator, caused by the variations in electricity demand and wind power.

The summation of $Q^{g}$ and $Q^{L}$ should be zero, assuming no heat loss to the environment (Eq. 26).

$$
Q^{g}+Q^{L}=0
$$

\subsubsection{Economical Evaluation}

Finally, the objective function is defined as follows:

$$
\begin{array}{r}
\text { Profit }=\left(D^{\text {Res }}-D^{\text {Plant }}\right) P^{E}-\left(N G^{P L}-N G^{E X P T}\right) P^{N}-P^{C} C \\
-\left(F O M^{C T}+V O M^{C T}\right) P^{C T}-\left(F O M^{G T}+V O M^{G T}\right) P^{G T}
\end{array}
$$

where $P^{E}, P^{N}$, and $P^{C}$ represent energy price $(\$ / \mathrm{MWh})$, natural gas price $(\$ / \mathrm{kg})$, and coal price $(\$ / \mathrm{kg})$, respectively. Variable operating and maintainance (VOM) 
costs of the coal- and gas-fired power generation units are represented by $V O M^{C T}$ and $V O M^{G T}$ while fixed operating costs (FOM) are presented by $F O M^{C T}$ and $F O M^{G T}$ for the coal- and gas-fired power units, respectively. In this investigation, the same $V O M$ and $F O M$ costs are assumed for both power generation types and are equal to 7.3 and 10.2 dollar per $M W h$ of energy production, respectively [36]. An hourly energy price is also assumed in this work with a trend shown in Figure 2 The credit given to export of the natural gas is considered to be the same as the purchasing price of the imported natural gas and is equal to $\$ 5.19 / 1000 \mathrm{ft}^{3}$ [29]. A price of $\$ 12.65 /$ ton is presumed for the coal.

It should be noted that the energy storage capability of the CCC process is expected to benefit the wholesale electricity prices in a power grid. However, no impact on the energy price is assumed. The impact of the energy storage on the wholesale electricity prices is outside the scope of this study.

\subsection{Controlled variable}

The overall power generation from the coal, gas, and wind should always match the sum of the electricity demands for the residential users and the CCC and LNG production facilities, as shown with Eq. 28

$$
P^{T o t}=D^{T o t}
$$

To achieve this goal, excess energy production is defined as shown in Eq. 29) and it is considered as a controlled variable with high and low set point values of zero. This also permits to dedicate a higher penalty for underproduction of power. Selection of a value of zero for the high and low set points of excess energy production highlights that neither overproduction nor underproduction of power is an optimal solution in practice.

$$
P^{E x}=P^{T o t}-D^{T o t}
$$




\subsection{Constraints}

350 in operation at each time step. This depends on the economic evaluation of each time step. The constraint developed in Eq. 30 helps the optimization algorithm choose between the operational strategy at each time step:

$$
L N G^{\text {To Tank }} L N G^{\text {From Tank }}=0
$$

While this constraint assumes that either $L N G^{\text {To Tank }}$ or $L N G^{\text {From Tank }}$ is zero 355 at each time step, $L N G^{B Y P}$ always has non-zero values. This is because of the continuous demand of LNG to the CCC plant for the treatment of $\mathrm{CO}_{2}$ produced from the power plant. It is also unlikely that import and export of natural gas occur simultaneously in practice. Thus, a similar relationship is assumed between them:

$$
N G^{P L} N G^{E X P T}=0
$$

Additionally, a capacity of 8 million $\mathrm{kg}$ is assumed for the LNG tank in this investigation. At the tank temperature and pressure of $-94{ }^{\circ} \mathrm{C}$ and 37 bar, respectively, a standard capacity of $28000 \mathrm{~m}^{3}$ can hold 8 million $\mathrm{kg}$ of LNG. This capacity is selected based on the performance of the integrated system. However, the overall performance of the hybrid system remains the same with different tank capacities [29]. Thus:

$$
L N G^{\text {Tank }} \leq 8 \times 10^{6}
$$
noted that the assumed electricity demand profile has a large range of variation (838 to $2000 \mathrm{MW}$ ). Because the gas and steam turbines considered in this work are the main energy sources during peak hours and the steam turbine is anticipated a baseline unit, it is not possible to meet the peak of the residential electricity demand 
without a large gas turbine. With current technologies, such a large fluctuation in electricity demand is met through several peaking generation units. Thus the need for oversized gas or oil turbines is eliminated. With a single power generation unit it is not possible to meet the large gap between maximum and minimum electricity demand. The need to optimize load flowing capacity highlights the importance of simulating a power grid in which the fossil-fueled power generation units are equipped with the CCC process. In this case, peak electricity demand is met through a combination of power sources. In addition, the energy storage portion of CCC can effectively become the grid spinning reserve by adjusting its parasitic load in time to accommodate the dispatch schedule of the grid. This large-scale energy storage capacity has the potential for significant economic and operational benefit. Study of a large scale power grid system when fossil-fueled power generation units are equipped with the CCC process is the focus of future work. For the purpose of a single generation unit, it is assumed that a large capacity for the gas turbine is a valid assumption.

$$
P^{G T} \leq G T^{c a p}
$$

From [29], it is also presumed that the combined electricity consumption in the CCC and LNG production facilities is less than $15 \%$ of the upper bound for the steam boiler power output (1800 MW).

$$
D^{\text {plant }} \leq 270
$$

As stated before, it is presumed that the set point of power production in the steam turbine $\left(P^{S P}\right)$ can vary from 800 to $1800 \mathrm{MW}$. While no economic calculation is considered to size the steam turbine, these values are selected based on the maximum residential demand assumed in this investigation. However, an estimate of the required nominal power output for the steam turbine is obtained from the results.

\subsection{Optimization Framework}

After formulating the system, it is necessary to set up an optimization framework to increase the effectiveness of the hybrid system. The optimization framework used 
in this system benefits from an objective function in the form of an $\ell_{1}$-norm because it permits prioritization of the objective functions and only linear terms are added to the problem. An $\ell_{1}$-norm approach is formulated as shown in Eq. 35] [29, 40, 41]. In this equation, a desired objective function for the problem (Eq. 27) is added to the expression presented by Eq. [35a) and forms the overall objective function. The mathematical equation presented by Eq. $35 \mathrm{a}$ ) is used for model regularization to obtain satisfactory results; i.e., in each simulation, variables $c_{\bar{y}}, c_{u}, c_{\Delta u}$ are adjusted such that smooth results are observed in the trend of the decision variables. Thus, these variables are the tuning parameters for the model. High penalization factors are also assigned for the deviation of the controlled variable from the desired set point. The penalization factors are $w_{h i}$ and $w_{l o}$ to penalize over and under production of power, respectively. Eqs. 35b to 35d represent the model of the system developed in Sections 3.1 to 3.3 Eqs. $35 \mathrm{e}$ and $35 \mathrm{f}$ also represent the path that the optimization algorithm uses to achieve the desired set point for the controlled variable. The expressions presented by Eqs. $35 \mathrm{~g}$ and $35 \mathrm{~h}$ permit the optimizer to keep the controlled variable within a deadband without penalization.

$$
\begin{gathered}
\min J=w_{h i}^{T} \cdot e_{h i}+w_{l o}^{T} \cdot e_{l o}+y_{m}^{T} \cdot c_{\bar{y}}+u^{T} \cdot c_{u}+\Delta u^{T} \cdot c_{\Delta u} \\
\text { s.t. } \quad 0=f\left(\frac{\delta x}{\delta t}, x, \bar{y}, p, d, u\right) \\
0=g(x, \bar{y}, p, d, u) \\
0 \leq h(x, \bar{y}, p, d, u) \\
\tau_{c} \frac{\delta y_{t, h i}}{\delta t}+y_{t, h i}=S P_{h i} \\
\tau_{c} \frac{\delta y_{t, l o}}{\delta t}+y_{t, l o}=S P_{l o}
\end{gathered}
$$




$$
\begin{aligned}
& e_{h i} \geq\left(\bar{y}-y_{t, h i}\right) \\
& e_{l o} \geq\left(y_{t, l o}-\bar{y}\right)
\end{aligned}
$$

where the nomenclature for Eq. [35] is found in Table 2

Table 2: Nomenclature for general form of the objective function with $\ell_{1}$-norm formulation 29

\begin{tabular}{cl}
\hline Symbol & Description \\
\hline$J$ & objective function \\
$\bar{y}$ & model values $\left(\overline{y_{0}}, \ldots, \overline{y_{n}}\right)^{T}$ \\
$y_{t, h i}, y_{t, l o}$ & trajectory dead-band for target values \\
$w_{h i}, w_{l o}$ & penalty factors outside trajectory dead-band \\
$c_{\bar{y}}, c_{u}, c_{\Delta u}$ & cost of variables $y, u$, and $\Delta u$, respectively \\
$u, x, p, d$ & inputs $(u)$, states $(x)$, parameters, and disturbances $(d)$ \\
$f, g, h$ & equation residuals $(f)$, output function $(g)$, and inequality \\
& constraints $(h)$ \\
$\tau_{c}$ & time constant of desired controlled variable response \\
$S P_{l o}, S P_{h i}$ & lower and upper bounds to final set point dead-band \\
$e_{h i}, e_{l o}$ & slack variable above or below the trajectory dead-band \\
\hline
\end{tabular}

The set of equations in Eq. 35] is implemented in the APMonitor Modeling Language [42] and solved either with an interior point solver (IPOPT) [43] or an active set solver (APOPT) 44, 45, 46, 47, 48. More information about how to implement an optimization in the APMonitor Modeling Language can be found in [40].

This optimization problem is solved for eight days of simulation time with hourly time increments. Trends of the variables during the three or four middle days are considered that of an infinite time horizon. This ensures that the performance of the system is not affected by the boundary conditions. More details about this approach are available in [29].

425

As mentioned before, the purpose of this investigation is to integrate the CCC process with a baseline steam turbine. To achieve this goal, a large penalization fac- 
tor, $c_{\Delta u}$, is dedicated to the variation of set point of the steam turbine power output, $\left(P^{S P}\right)$. In this case, the steam turbine power output does not vary unless there is an improvement in the overall objective function. In addition, the change in steam turbine power output between subsequent time steps is limited to $100 \mathrm{MW} / \mathrm{hr}$ to further restrict the variation of the power output in the steam turbine. This maximum change rate is much less than $1 \% / \mathrm{min}$ of the nominal load-following capacity of the steam turbine.

\section{Results and Discussion}

The results for the integration of cryogenic carbon capture with a baseline coalfired power plant are presented in this section. These results are divided into four sections; first, the trend of power production from different sources is presented. The total electricity demand is met through a combination of power supplies while steam turbine has the performance of a baseline power generation unit. The net trends of the import of natural gas to the plant and LNG inventory in the tank show that natural gas is imported to the plant when electricity is cheap while it is exported during periods with high electricity prices. LNG inventory in the tank also reflects an excellent transient response to the fluctuations in residential demand, energy price, and wind power availability. Trends of electricity demand for different components of the CCC and LNG plants show effective time-shifting of the demand of the mixed refrigerant compressor. Finally, the profitability of the baseline hybrid system is compared with a case study for which steam turbine operates as a loadfollowing unit.

\subsection{Power Production}

Figure 3 presents the total power generation in the steam turbine. For comparison, the power generation from a load-following steam turbine is also shown in Figure 3. As it is observed, total power generated in the steam turbine does not vary significantly for most of the simulation time. The minimum output for the steam turbine $(820 \mathrm{MW})$ is close to the selected lower limit $(800 \mathrm{MW})$. Because the steam 

end of the simulation time, wind power has a smaller contribution in meeting the electricity demand and it is found more economical to increase the power output from the steam boiler.

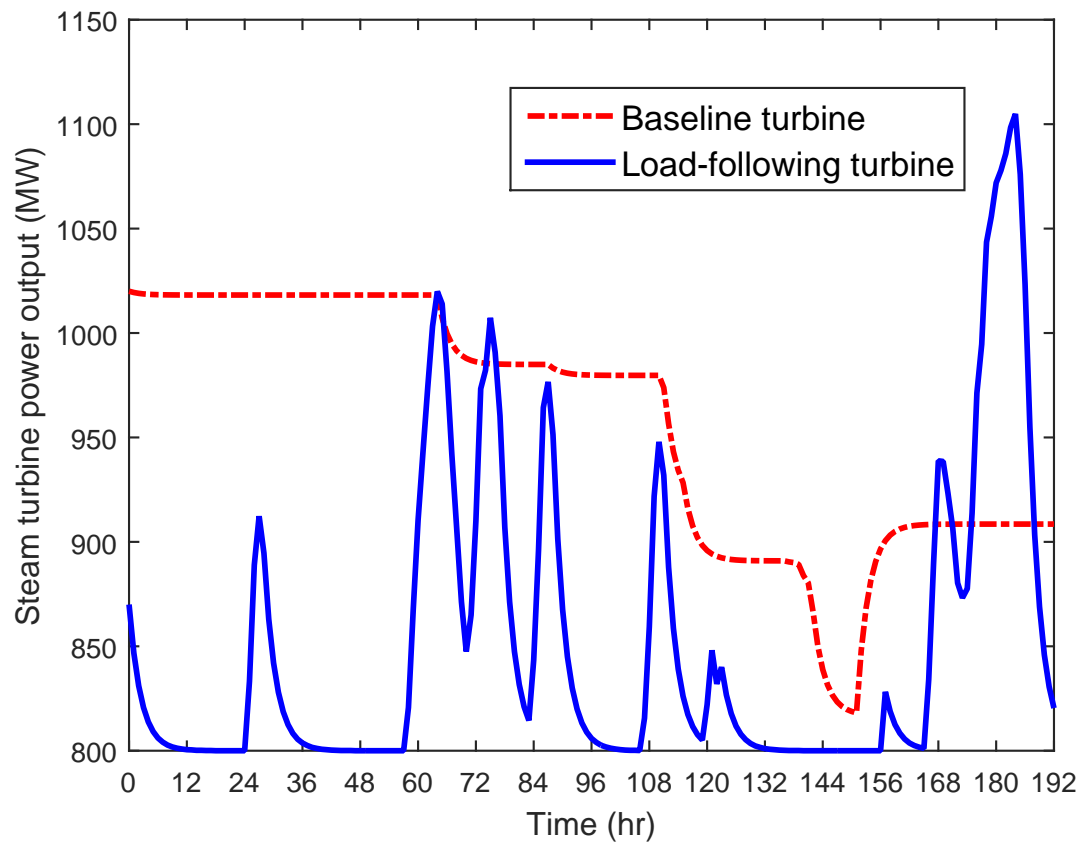

Figure 3: Total power generation from the steam turbine 


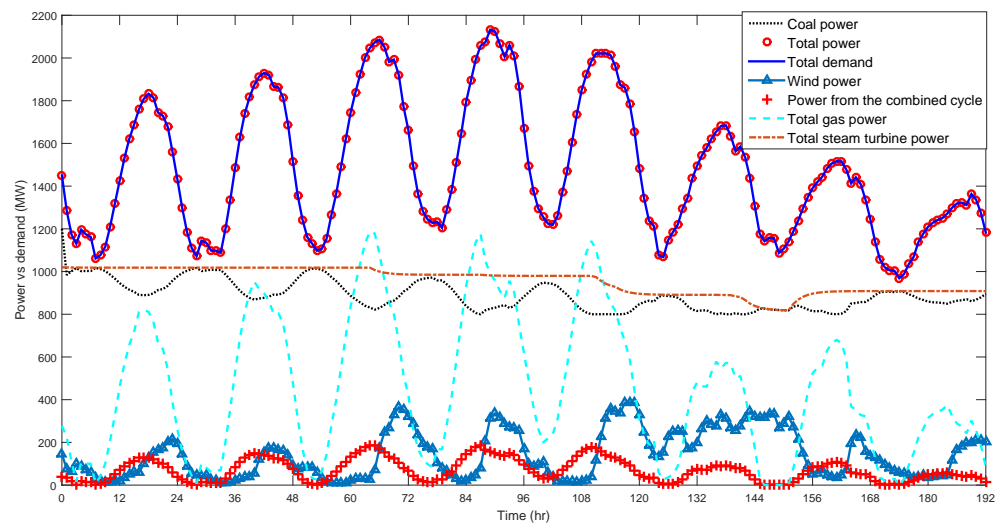

Figure 4: Electricity demand and power production from coal, wind, and natural gas in a gas turbine.

From Figure 3 it seems that a value of $1020 \mathrm{MW}$, the maximum output from the steam turbine, is reasonable to meet the combined electricity demand of the 
residential users and CCC plant. However, economical calculations are needed with

consideration of the life time of the steam turbine and the growing need in electricity demand to accurately size it.

\subsection{Net Import of Natural Gas vs. Tank Inventory}

Trends of variables for the natural gas imported and exported to the plant are shown in Figure 5a. Import of natural gas to the plant is mainly observed when electricity is cheap. Export of natural gas from the plant, on the other hand, occurs when electricity is relatively expensive. This permits the system to avoid liquefying the circulating natural gas $\left(N G^{C C C}\right)$ when demand in electricity is high. Trends of LNG inventory in the tank (Figure $5 \mathrm{~b}$ ] reflect an excellent transient response of this optimization problem to fluctuations in residential demand, energy price, and wind power availability. LNG inventory in the tank is dependent on the energy price, current inventory in the tank, wind power availability, and the penalization factors used for the natural gas imported to and exported from the plant. Thus, LNG inventory is a cumulative effect of these factors and is less intuitive to accurately attribute its trend to each of these factors. However, it is expected to store LNG when higher electricity price or lower wind availability are anticipated. For instance, when two peaks in the electricity price are anticipated between hours 86 and 92, LNG storage starts before actually reaching the peak at hour 86. In this case, LNG storage starts at hour 71 and ends at hour 79 when it reaches the maximum storage capacity of the tank. Stored LNG is then recovered from the tank until the tank is emptied at hour 124. This period includes the hours for which the peak of electricity price actually occur. LNG storage is started again after hour 125; however, more wind power is available from hour 123 to 144 and the tank is not filled completely. This is because the more availability of wind power is utilized to meet the power demand and less power is produced from the fossil fuels (consequently less $\mathrm{CO}_{2}$ is produced). After hour 152, on the other hand, wind power is less available and it is seen that the LNG tank is fully filled before reaching hour 152. A reasonable cycling in the trend of LNG inventory is also observed after hour 152 and in the first 72 hours.

While the penalization factors are used to smooth the trends of variations in nat- 


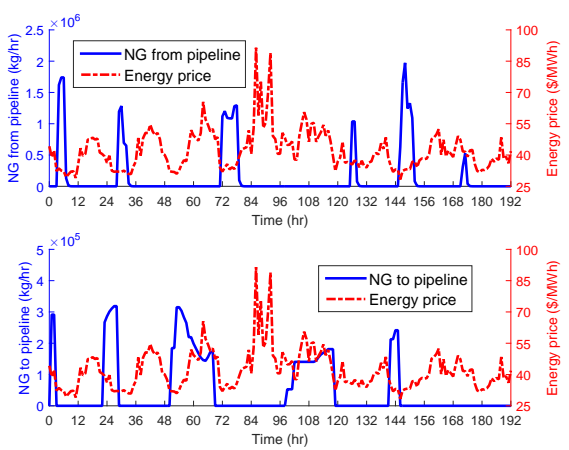

(a) Natural gas imported to and exported from the plant

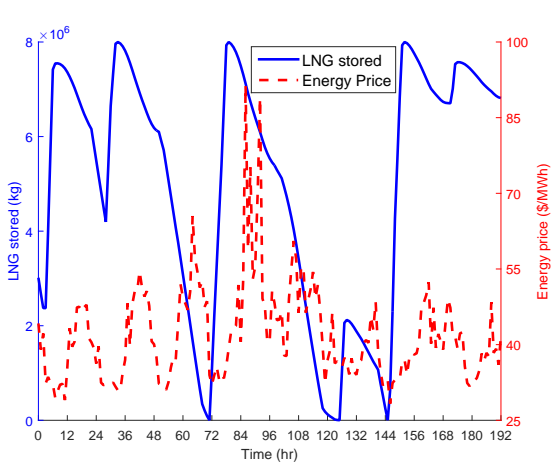

(b) LNG inventory

Figure 5: Trend of natural gas and LNG inventory

ural gas to and from the plant, the overall trends for these variables and LNG inven- 


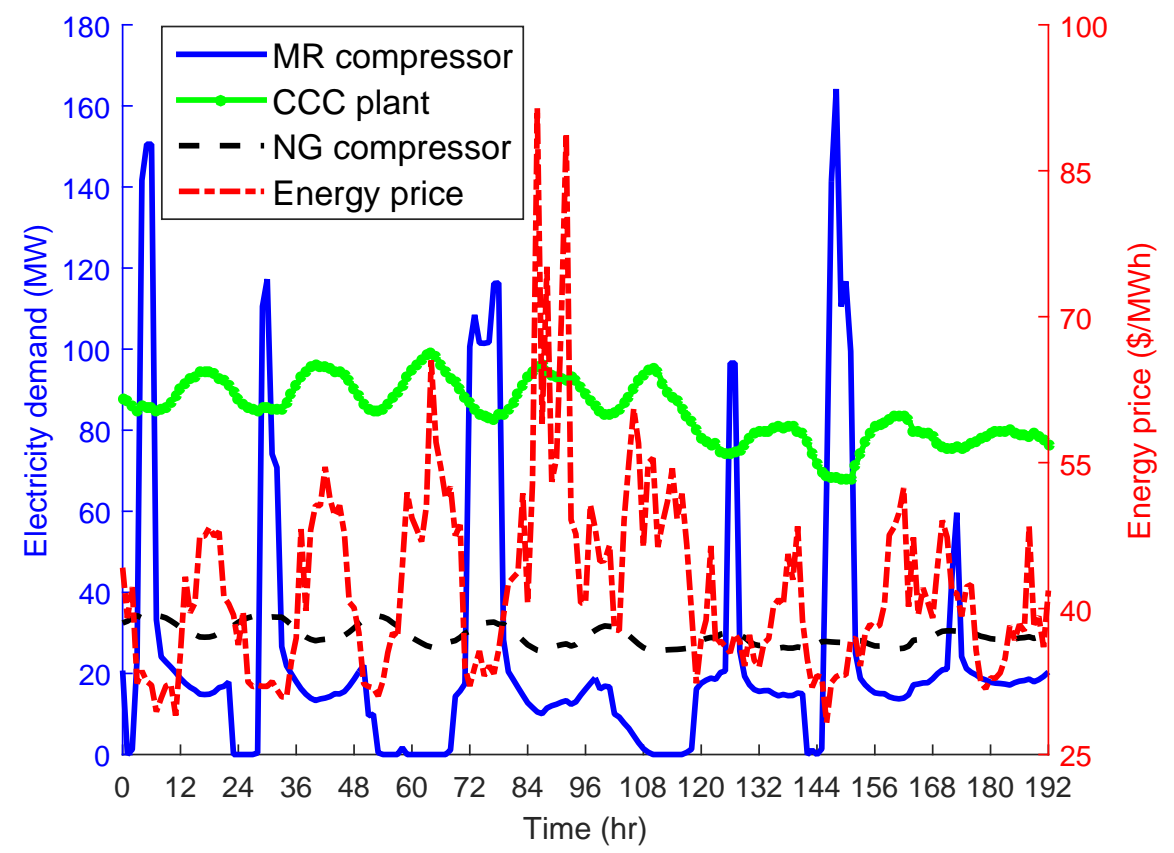

Figure 6: Electricity demand for refrigeration compressors and CCC plant in a combined cycle power generation unit with energy storage

\subsection{Economic Evaluation}

The average profit obtained for a baseline steam turbine over the selected days is $\$ 6.5 \mathrm{k} / \mathrm{hr}$. This is compared to $\$ 13.6 \mathrm{k} / \mathrm{hr}$ obtained when the power output from

the steam turbine is allowed to vary without penalization. When the steam turbine is allowed to vary, penalization factor for the variation of power output, $c_{\Delta u}$ in Eq. [35a), relaxes; thus, the hybrid system obtains a new optimum. Optimization of the variable steam turbine results in an average profit of $\$ 13.6 \mathrm{k} / \mathrm{hr}$. The average hourly revenue obtained from both baseline and variable steam turbines is constant and equals $\$ 58 \mathrm{k} / \mathrm{hr}$. This is constant because residential electricity demand and rates are fixed inputs to the optimization problem.

The ratio of total profit and total energy production from all sources considered over the simulation time is $0.43 \mathrm{c} / \mathrm{kWh}$ for a baseline case while it is $0.91 \mathrm{c} / \mathrm{kWh}$ for a variable steam turbine. When fixed and variable operating and maintenance costs of the coal- and gas-fired power generation units (VOM and FOM) are ignored in Eq. 
[27, the average profit for the baseline case is approximately $\$ 29 \mathrm{k} / \mathrm{hr}$ which is $20 \%$ less than the average profit of a load-following steam turbine $(\$ 35.5 \mathrm{k} / \mathrm{hr})$. Similarly, the ratio of the total profit and total energy production when $V O M$ and FOM are ignored in Eq. 27) is $1.92 \mathrm{c} / \mathrm{kWh}$ and $2.40 \mathrm{c} / \mathrm{kWh}$ for baseline and load-following steam turbines, respectively.

\section{Comparison between combined and simple cycles}

To emphasize on the significance of energy storage, the results obtained in Section 4 (scenario 1) are compared with a case study for which a baseline steam turbine is integrated with a simple cycle gas turbine (scenario 2); i.e. gas turbine exhaust does not generate power in scenario 2. In addition, natural gas supply for the gas turbine in scenario 2 is not the vaporized LNG exiting from the CCC process. In this case, the gas turbine serves as an independent peaking unit. However, it is still assumed that the CCC process treats the flue gas generated from the natural gas turbine. Because a simple cycle is assumed, treatment of the gas turbine exhaust is achieved by adding it to the coal exhaust after the coal superheaters and reheaters. The capacity of the gas turbine in scenario 2 is assumed the same as the analysis discussed in scenario $1(1000 \mathrm{MW})$. In scenario 1, the baseline performance is achieved through a combination of the steam generated from the coal and natural gas flue gas; i.e. when coal power in Figure 4 is at a maximum, power from the combined cycle is at a minimum and the reverse trend is also observed. In scenario 2 , however, the baseline performance is achieved merely from the steam generated from coal combustion (coal power). Thus, more coal is combusted in the steam boiler in a simple cycle to achieve the same steam flow rate and power output as a combined cycle. To make a fair comparison, it is assumed that the power output obtained in scenario 1 for the steam turbine, $P^{S T}$, is an input to scenario 2 and it is not varied; i.e. rate of steam production is the same for both scenarios. In addition, it is assumed in scenario 2 that energy storage is not available. This case represents a typical power generation unit that is equipped with a carbon capture technology (without storage capability) and a peaking unit to capture the $\mathrm{CO}_{2}$ emissions while 
meeting the electricity demand.

With these assumptions, optimization of the system presented in scenario 2 is implemented and the results are compared with scenario 1 . In both scenarios, power production from coal and gas is considered a single generation unit and the power supply is used to meet the electricity demand of residential users and the CCC plant. s5 Figure 7 shows the trend of power production from each source for scenario 1. Figures $8 \mathrm{a}]$ and $8 \mathrm{~b}$ also represent the trends of excess power production in each scenario. It is seen in scenario 2 that for most of the simulation time, power supply equals the electricity demand. However, both over production and under production of power occur (Figure 8b) despite the penalization factors applied to balance the demand and supply of electricity. For scenario 1, it is observed that there is no mismatch between electricity demand and power supply over the horizon (Figure 8a). While the observations seen in scenario 2 are rare when a grid analysis is implemented (due to the presence of peaking units), this comparison highlights the importance of energy storage of the CCC process. Energy storage adds flexibility to a single coal-fired generation system to operate as a baseline unit and still be able to meet the peak electricity demand without relying on other generation units in the grid.

The overall mass flow rate of the coal combusted for steam production in a simple cycle is $8 \%$ more than a combined cycle, as was expected. Total electricity consumption of the plant is also $8 \%$ more in scenario 2 . This is because scenario 2 produces more flue gas from coal consumption to achieve the same steam flow rate as in scenario 1 . Unlike scenario 1 , the total flow rate of natural gas imported and exported to the pipeline in scenario 2 is zero because there is no opportunity for arbitrage of electricity without energy storage (see Figure 9) and time-shifting of the electricity demand of mixed refrigerant compressor is not achievable. Thus, natural gas consumption in the simple cycle power generation unit is merely for the purpose of meeting the peak total electricity demand. In contrast, in the case of a combined cycle with energy storage, natural gas has the dual purposes of serving as the refrigerant and a fuel. Thus, natural gas is imported and exported from the plant to take advantage of the arbitrage of electricity (Figure 6). A comparison between the profitability of these two scenarios is meaningless because the primary goal of meeting 


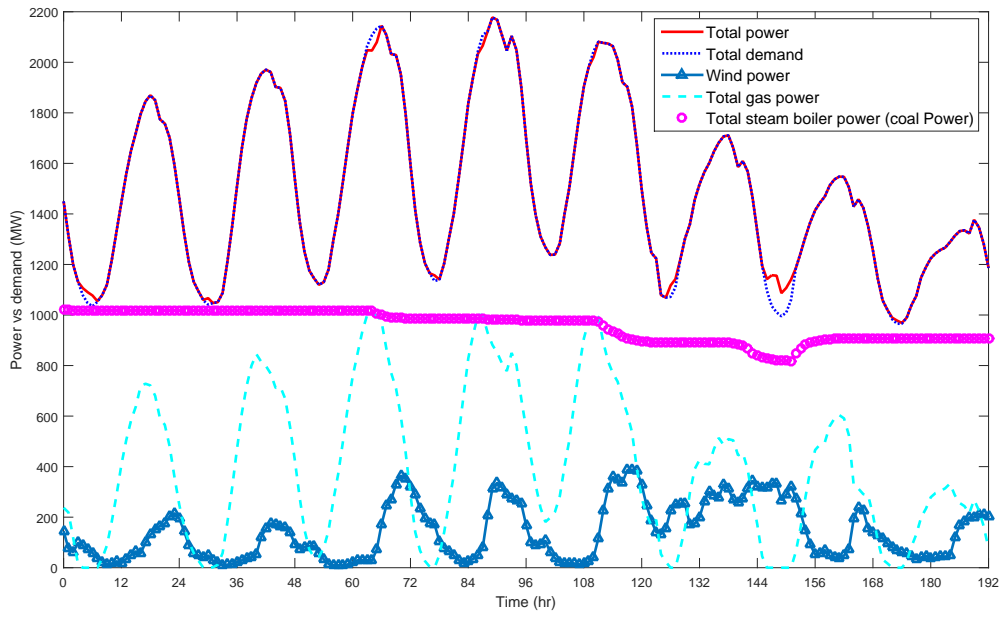

Figure 7: Electricity demand and power production from coal, wind, and natural gas in a simple cycle power generation unit without energy storage (Scenario 1)
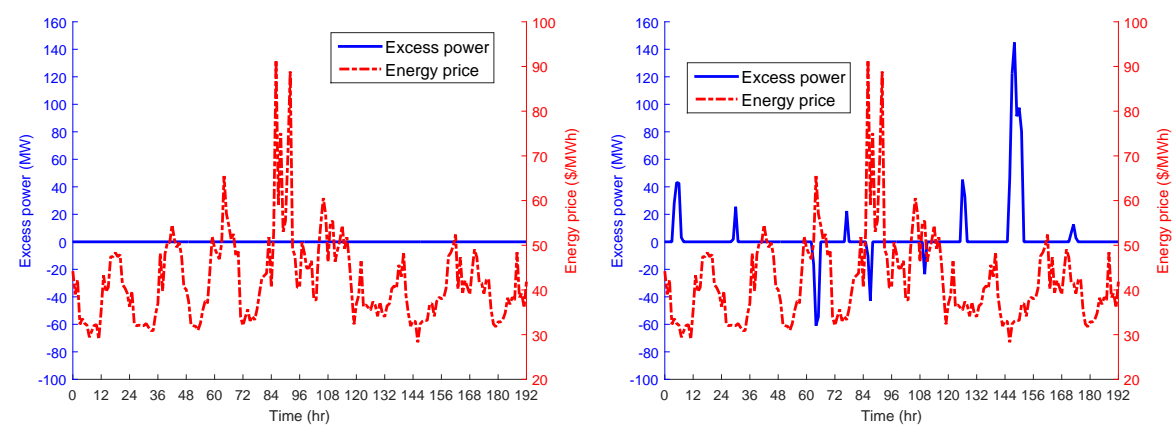

(a) Combined cycle power generation with (b) Simple cycle power generation without energy storage (Scenario 1) energy storage (Scenario 2)

Figure 8: Excess power comparison between combined and simple power generation cycles with and without energy storage, respectively 


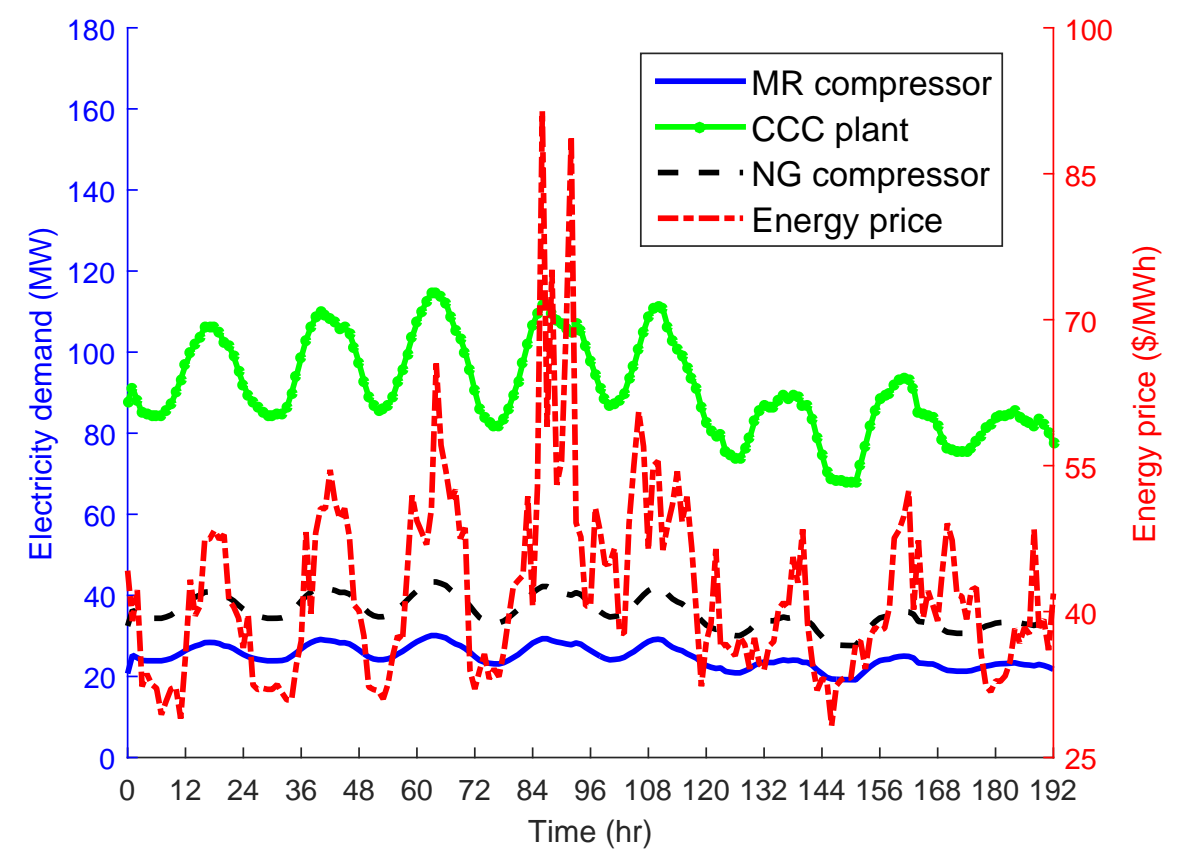

Figure 9: Electricity demand for refrigeration compressors and CCC plant in a simple cycle power generation unit without energy storage

the electricity demand at all time steps over the horizon is not achieved in scenario 2. Table 3 summarizes the main results obtained from both scenarios.

\section{Comparison of cycling costs}

An important aspect of power plant operation is the cost associated with ramping, also known as load following or cycling. The changes in operational levels of the plant result in increased thermal, pressure, and mechanical related stress and fatigue [49, 50]. This leads to increased equipment degradation and associated operation and maintenance costs, as well as decreased thermal efficiency.

In general, research done on ramping in power plants has looked at the most fragile part of the plant, the turbine rotor. Historically unit commitment models with economic dispatch have incorporated fixed ramp-rate constraints with the assumption that ramping between the constraints will not cause damage to the turbine rotor [51 52]. In 2012, a report published by National Renewable Energy Laboratory 
Table 3: Comparison between simple and combined cycles: Variables integrated over 8 days of simulation

time

\begin{tabular}{ccc}
\hline Variable & Simple cycle & Combined cycle \\
\hline Total mass of combusted coal $(k g)$ & $70,794,000$ & $65,519,000$ \\
Total mass of combusted natural gas $(k g)$ & $15,422,000$ & $14,842,000$ \\
Total revenue $(\$)$ & $11,211,000$ & $1,1211,000$ \\
Total $\mathrm{CO}_{2}$ production $(k g)$ & $197,700,000$ & $184,490,000$ \\
Total CO 2 captured $(k g)$ & $177,930,000$ & $166,041,000$ \\
Total power production from coal $(M W h)$ & 183,810 & 170,110 \\
Total power production from natural gas $(M W h)$ & 75,605 & 86,336 \\
Total power production from wind power $(M W h)$ & 27,291 & 27,291 \\
Total power production from all sources $(M W h)$ & 286,750 & 283,760 \\
\hline
\end{tabular}

[53] investigated the cost of ramping for an entire plant by considering the cycling

costs of several power generation types [54]. This report provides a lower bound for the cycling costs of eight types of generation units. The cycling costs are reported for different cycling scenarios including cold start, warm start, hot start, and loadfollowing cases. Between these cycling scenarios, cold start and load-following have the highest and lowest cycling costs, respectively. For instance, the lower bound for the cold start cycling costs of a typical large-scale subcritical coal-fired power plant is \$ $105 / M W$ capacity per cold start while load-following cycling cost for the same generation type is $\$ 2.45 / M W$ capacity per load follow [54]. While startup scenarios impose the most expensive cycling costs of the power plants, it is not the scope of this work to investigate them. Consideration of such scenarios requires a longer simulation time (e.g. one year) to be taken into consideration. Instead, just the impact of cryogenic carbon capture on the cycling costs due to load-following of the coaland gas-fired power generation units is considered. According to [54], the cycling cost of a generation unit varies between individual plants and the numbers provided in this report are generic lower bounds. In this study, estimated multiplicative factors are also provided for faster ramp rate. These multiplicative factors, however, 
are not considered in this study and the cycling costs are the median capital and maintenance costs of typical ramping rates. This investigation considers the loadfollowing cycling costs of large scale subcritical coal-fired and natural gas combined cycle (NGCC) power generation units. Accordingly, the cycling cost associated with load-following of a coal-fired generation unit is $\$ 2.45 / M W$ capacity per load follow while it is $\$ 0.64 / M W$ capacity for a NGCC power plant. To calculate the number of cycles for power generation from both coal and gas, a post-processing approach is considered; i.e. power outputs from solving the optimization problem are used as input to the rainflow cycle counting algorithm [55] where the output from the algorithm is the number of cycles. This calculation assumes that power output from the optimization results has a similar trend to overall stresses in the boiler. The rainflow algorithm allows the application of Miner's rule to assess the fatigue life of a structure subject to complex loading. More details about the rainflow algorithm are available in [56].

With the abovementioned assumptions, the cycling costs of the baseline and load-following steam turbines are considered. The power outputs from the coaland gas- fired generation units, $P^{S T}$ and $P^{G T}$, for both scenarios are used in the rainflow cycle counting software developed in [57]. Consequently, the number of cycles for the load-following scenario for the coal- and gas- fired generation units are found to be 20 and 17, respectively, over 8 days of simulation time. For a baseline scenario, there are 1 and 21 cycles in the power output from the coal- and gas- fired generation units, respectively. Optimization of the baseline and loadfollowing coal-fired generation units result in a maximum power output of 1020 $M W$ and $1210 \mathrm{MW}$, respectively. As mentioned previously, sizing of the generation units is beyond the scope of this study and requires extensive study. However, it is assumed that a capacity of $1800 \mathrm{MW}$ is a good estimate for both loadfollowing and baseline coal-fired generation unit for the purpose of cycling costs comparison. With this capacity, the cycling costs of the coal-fired unit for the loadfollowing scenario is $1800 \times 2.45 \times 20=\$ 88200$ for 8 days of simulation time while it is $1800 \times 2.45 \times 1=\$ 4410$ for a baseline case study. In addition, the cycling cost of the load-following scenario for the gas-fired unit is $1000 \times 0.64 \times 17=\$ 10880$ comparing 
Table 4: Summary of cycling costs

\begin{tabular}{ccccc}
\hline & \multicolumn{2}{c}{ With wind } & \multicolumn{2}{c}{ Without wind } \\
\hline & $\begin{array}{c}\text { Load-following } \\
\text { boiler }\end{array}$ & $\begin{array}{c}\text { Baseline } \\
\text { boiler }\end{array}$ & $\begin{array}{c}\text { Load-following } \\
\text { boiler }\end{array}$ & $\begin{array}{c}\text { Baseline } \\
\text { boiler }\end{array}$ \\
\hline $\begin{array}{c}\text { No. Cycles in boiler } \\
\text { (Cost) }\end{array}$ & 20 & 1 & 18 & 1 \\
$(\$ 88200)$ & $(\$ 4410)$ & $(\$ 79380)$ & $(\$ 4410)$ \\
\hline No. Cycles in gas turbine & 17 & 21 & 23 & 15 \\
$($ Cost $)$ & $(\$ 10880)$ & $(\$ 13440)$ & $(\$ 14720)$ & $(\$ 9600)$ \\
\hline Total cycling costs & $\$ 99080$ & $\$ 17850$ & $\$ 94100$ & $\$ 14010$ \\
\hline
\end{tabular}

to a value of $1000 \times 0.64 \times 21=\$ 13440$ for a baseline case over 8 days of simulation. In summary, the total costs associated with the cycling of all generation units considered in this investigation are $\$ 99080$ and $\$ 17850$ for load-following and baseline scenarios, respectively, over 8 days of simulation time. The total costs of cycling for the same power generation units in the absence of wind power are $\$ 94100$ and $\$ 14010$ for the load-following and baseline coal-fired generation unit, respectively. These costs are based on 1 and 15 cycles for the coal-and gas-fired generation units, respectively, in a baseline case while 18 and 23 cycles are observed for the the same units, respectively, in a load-following case. Table 4 summarizes these results.

The saving in the cycling costs of the baseline generation units, in the presence and absence of wind power, is also a direct result of the energy storage of cryogenic carbon capture. It is well known that coal-fired generation units are mainly designed for baseline operation. Equipping the coal-fired power plant with cryogenic carbon capture enables the power generation unit, as a whole, to follow the load without necessarily varying the steam turbine output. This is achieved by supplying the natural gas required for the peaking unit from the storage system while the carbon dioxide separation from both generation units remains in operation. 
It should be emphasized that these costs are the generic lower bounds for cycling of the power generation units, and it does not consider the more expensive practices of cold, warm, and hot starts. In addition, it is unlikely to have this many cycles in the boiler in 8 days to follow the load in practice (for both baseline and load-following power generation units). This is because supplemental peaking units are used to avoid the variations in power output from the coal-fired generation units. While more accurate analysis of the number of cycles requires longer simulation horizon, this study demonstrates the potential reduction in cycling costs of a coal-fired power generation unit by utilizing the energy storage of the CCC process.

\section{Conclusion}

This investigation considers dynamic integration of a baseline fossil-fueled power generation unit with cryogenic carbon capture. Flue gas cools to the point of $\mathrm{CO}_{2}$ desublimation to separate $\mathrm{CO}_{2}$ from the remaining gases. The refrigeration cycles are energy intensive. However, with the energy storage of the CCC process, the electricity demand of the refrigeration cycle is shifted to off-peak hours; i.e. refrigerant required to drive the CCC process, LNG in this investigation, is produced in excess when electricity demand is low or wind power is available. Stored LNG is then used during peak hours to drive the CCC process. Thus, the compressors of the refrigeration cycles are operating at reduced loads during peak hours. Effective time-shifting of the electricity demand of the refrigeration compressors is observed from solving this optimization problem. The total electricity demand of the residential users and the CCC plant is met through a combination of power sources. Wind power, whenever available, is first used in meeting the demand. This leads to $100 \%$ utilization of the wind power. With the energy storage of cryogenic carbon capture, a single coalfired generation system is able to operate as a baseline unit and still be able to meet the peak electricity demand. Energy storage also enables a potential $82 \%$ and $85 \%$ decrease in the costs associated with load-following of power generation units in presence and absence of wind power, respectively. Consideration of a power grid in which the fossil-fueled power generation units are equipped with the CCC process 
is the focus of future work.

\section{Acknowledgments}

Financial and technical support from Sustainable Energy Solutions (SES), without which this work could not have been undertaken, are greatly appreciated. Authors are also thankful for the essential engineering data from the graduate students at Brigham Young University working on the Cryogenic Carbon Capture process ${ }^{\mathrm{TM}}$.

\section{References}

[1] International Energy Agency, $\mathrm{CO}_{2}$ Emissions from Fuel Combustion, Edition 2014, http://www.iea.org/statistics/onlinedataservice/ (accessed November 2015).

[2] Trends in global $\mathrm{CO}_{2}$ emissions, Tech. rep.,

http://edgar.jrc.ec.europa.eu/news_docs/ jrc-2014-trends-in-global-co2-emissions-2014-report-93171. pdf. (accessed November 2015).

[3] Carbon pollution emission guidelines for existing stationary sources: Electric utility generating units, Federal Register 80 (205) (2015) 64661-65120.

[4] A European Strategic Energy Technology Plan (SET-PLAN) Towards a Low Carbon Future, Document 52007DC0723, Tech. rep., Europian Union Legislation (2007).

[15] Climate Summit 2014, http://www .un.org/climatechange/summit/2014/ 09/2014-climate-change-summary-chairs-summary/ (accessed November 2015).

740

[6] World coal trade,https://www.eia.gov/todayinenergy/detail.cfm?id= 23852 (accessed February 2016).

【 [7] Europian Union Legislation, Document 52007DC0019, http://eur-lex. europa.eu/legal-content/EN/NOT/?uri=CELEX:52007SC0008 (2007). 
[8] G. Xu, Y. ping Yang, J. Ding, S. Li, W. Liu, K. Zhang, Analysis and optimization of

[13] H. Chalmers, M. Leach, J. Gibbins, Built-in flexibility at retrofitted power plants: What is it worth and can we afford to ignore it?, Energy Procedia 4 (2011) 2596 -2603. doi:10.1016/j.egypro.2011.02.158

[14] S. M. Cohen, G. T. Rochelle, M. E. Webber, Optimizing post-combustion $\mathrm{CO}_{2}$

[15] S. M. Cohen, G. T. Rochelle, M. E. Webber, Optimal operation of flexible postcombustion $\mathrm{CO}_{2}$ capture in response to volatile electricity prices, Energy Pro$\mathrm{CO}_{2}$ capture in an existing coal-fired power plant in china, Energy 58 (0) (2013) 117 - 127. doi:http://dx.doi.org/10.1016/j.energy.2013.04.012.

[9] C. A. Kang, A. R. Brandt, L. J. Durlofsky, Optimal operation of an integrated energy system including fossil fuel power generation, $\mathrm{CO}_{2}$ capture and wind, Energy 36 (12) (2011) 6806 - 6820. doi:10.1016/j . energy . 2011 .10.015.

[10] P. G. Brodrick, C. A. Kang, A. R. Brandt, L. J. Durlofsky, Optimization of carboncapture-enabled coal-gas-solar power generation, Energy 79 (2015) 149 - 162. doi:http://dx.doi.org/10.1016/j.energy.2014.11.003

[11] C. A. Kang, A. R. Brandt, L. J. Durlofsky, Optimizing heat integration in a flexible coal-natural gas power station with $\mathrm{CO}_{2}$ capture, International Journal of Greenhouse Gas Control 31 (2014) 138 - 152. doi:http://dx.doi.org/10. 1016/j.ijggc.2014.09.019

[12] C. A. Kang, A. R. Brandt, L. J. Durlofsky, A new carbon capture proxy model for optimizing the design and time-varying operation of a coal-natural gas power station, International Journal of Greenhouse Gas Control (2015) -doi:http: //dx.doi.org/10.1016/j.ijggc.2015.11.023 capture in response to volatile electricity prices, Int. J. Greenh. Gas Control 8 (2012) 180 - 195. doi:http://dx.doi.org/10.1016/j.ijggc.2012.02. 011.

cedia 4 (2011) 2604-2611. doi:10.1016/j . egypro.2011.02.159 
[16] S. M. Cohen, G. T. Rochelle, M. E. Webber, Turning $\mathrm{CO}_{2}$ capture on and off in response to electric grid demand: A baseline analysis of emissions and economics, ASME Journal of Energy Resources Technology 132 (2010) 021003. doi:10.1115/ES2008-54296.

[22] C.-C. Cormos, Integrated assessment of IGCC power generation technology 795 $10.1016 /$ j.energy .2012.03.025.

[23] C.-C. Cormos, P. S. Agachi, Integrated assessment of carbon capture and storage technologies in coal-based power generation using CAPE tools, Com- 
puter Aided Chemical Engineering 30 (2012) 56 - 60. doi:10.1016/ B978-0-444-59519-5.50012-5.

[24] A. Gopan, B. M. Kumfer, J. Phillips, D. Thimsen, R. Smith, R. L. Axelbaum, Process design and performance analysis of a staged, pressurized oxy-combustion (SPOC) power plant for carbon capture, Appl. Energy 125 (2014) 179 - 188. doi:http://dx.doi.org/10.1016/j.apenergy.2014.03.032

[28] Sustainable Energy Solutions Company, http://sesinnovation.com/, (accessed November 2015).

[29] S. M. Safdarnejad, J. D. Hedengren, L. L. Baxter, Plant-level dynamic optimization of cryogenic carbon capture with conventional and renewable power I

820

[30] S. M. Safdarnejad, J. D. Hedengren, L. L. Baxter, L. Kennington, Investigating the impact of cryogenic carbon capture on the performance of power plants, in: Proceedings of the American Control Conference (ACC), Chicago, IL, 2015, pp. 5016-5021. doi:10.1109/ACC.2015.7172120 
[33] F. Fazlollahi, A. Bown, E. Ebrahimzadeh, L. L. Baxter, Design and analysis of the natural gas liquefaction optimization process- (CCC-ES) (energy storage of

[35] F. Fazlollahi, A. Bown, E. Ebrahimzadeh, L. L. Baxter, Transient natural gas liquefaction process comparison- dynamic heat exchanger under transient changes in flow, Energy (2015) submitted.

[36] Cost and Performance Baseline for Fossil Energy Plants Volume 1: Bituminous Coal and Natural Gas to Electricity, Tech. rep., National Energy Technology Lab-

[37] California Independent System Operator (CAISO), System Demand, CAISO Demand Forecast, http://oasis . caiso.com// (accessed February 2015).

[38] E. Ebrahimzadeh, P. Wilding, D. Frankman, F. Fazlollahi, L. L. Baxter, Theoretical and experimental analysis of dynamic plate heat exchanger: non-retrofit 850 configuration, Appl. Therm. Eng. 93 (2016) 1006 - 1019. doi:10.1016/j. applthermaleng.2015.10.017 
[39] E. Ebrahimzadeh, P. Wilding, D. Frankman, F. Fazlollahi, L. L. Baxter, Theoretical and experimental analysis of dynamic heat exchanger: Retrofit configuration, Energy 96 (2016) 545 - 560. doi : 10.1016/j . energy .2015.12.068.

[40] J. D. Hedengren, R. Asgharzadeh Shishavan, K. M. Powell, T. F. Edgar, Nonlinear modeling, estimation and predictive control in APMonitor, Comput. Chem. Eng. 70 (2014) 133 - 148. doi:10.1016/j.compchemeng. 2014.04 .013$.

[41] S. M. Safdarnejad, J. R. Gallacher, J. D. Hedengren, Dynamic parameter estimation and optimization for batch distillation, Computers \& Chemical Engineering 86 (2016) 18 -32. doi:10.1016/j . compchemeng. 2015.12.001.

[42] J. D. Hedengren, APMonitor Modeling Language, http://www.apmonitor. com/, (accessed November 2015).

[43] A. Wächter, L. T. Biegler, On the Implementation of a Primal-Dual Interior Point Filter Line Search Algorithm for Large-Scale Nonlinear Programming, Math. Program. 106 (1) (2006) 25-57. doi:10.1007/s10107-004-0559-y.

[44] J. D. Hedengren, J. L. Mojica, W. Cole, T. F. Edgar, APOPT: MINLP Solver for Differential Algebraic Systems with Benchmark Testing, in: Proceedings of the INFORMS Annual Meeting (2012), Phoenix, AZ, 2012.

[45] K. M. Powell, J. D. Hedengren, T. F. Edgar, Dynamic optimization of a solar thermal energy storage system over a 24 hour period using weather forecasts, in: American Control Conference (ACC), 2013, IEEE, 2013, pp. 2946-2951.

[46] K. M. Powell, J. D. Hedengren, T. F. Edgar, Dynamic optimization of a hybrid 口 solar thermal and fossil fuel system, Sol. Energy 108 (0) (2014) 210 - 218. doi : http://dx.doi.org/10.1016/j.solener.2014.07.004.

[47] A. N. Eaton, S. M. Safdarnejad, J. D. Hedengren, K. Moffat, C. B. Hubbell, D. V. Brower, A. D. Brower, Post-installed fiber optic pressure sensors on subsea production risers for severe slugging control, in: Proceedings of the ASME 
2015, $34^{\text {th }}$ International Conference on Ocean, Offshore and Arctic Engineering (OMAE), no. OMAE2015-42196, St. John's, Canada, 2015. doi:10.1115/

[48] J. D. Hedengren, A. N. Eaton, Overview of estimation methods for industrial dynamic systems, Optim. Eng. (2015) $1-24$, doi:10.1007/ s11081-015-9295-9.

[49] S. S. Manson, Behavior of materials under conditions of thermal stress, Tech. rep. (1954).

[50] J. L. F. Coffin, R. Wesley, A study of the effects of cyclic thermal stresses on a ductile metal, Tech. rep. (1954).

[51] A. I. Cohen, Modeling unit ramp limitations in unit commitment, in: Proceedings of the Tenth Power systems and Computing Conference, 1990, pp. 11071114 .

[52] C. Wang, S. Shahidehpour, Effects of ramp-rate limits on unit commitment and economic dispatch, IEEE Trans. Power Syst. 8 (3) (1993) 1341-1350.

[53] National Renewable Energy Laboratory (NREL), http://wind.nrel.gov/ Web_nrel/, (accessed November 2015).

[54] N. Kumar, P. Besuner, S. Lefton, D. Agan, D. Hilleman, Power Plant Cycling Costs, Tech. rep., National Renewable Energy Laboratory (2012).

[55] M. Matsuishi, T. Endo, Fatigue of metals subjected to varying stress, Presented to the Japan Society of Mechanical Engineers, Fukuoka, Japan, 1968.

[56] N. Mukhopadhyay, B. Dutta, H. Kushwaha, On-line fatigue-creep monitoring system for high-temperature components of power plants, Int. J. Fatigue 23 (6)

1. (2001) 549 - 560. doi:http://dx.doi.org/10.1016/S0142-1123(01) 00009-3

[57] J-Rain Free Rainflow Counting Software, http://www. jesmondengineering.com/engineering-software/ 
November 2015). 